\title{
BMJ Open Relationship between exposure to ozone and exacerbation requiring hospital admission among patients with asthma: a case-control study in central Taiwan
}

\author{
Ching-Heng Lin (D) , ${ }^{1,2,3,4}$ Li-Ting Wong, ${ }^{1}$ Jeng-Yuan Hsu, ${ }^{1,5,6}$ \\ Wen-Cheng Chao (iD) 7,8,9,10
}

To cite: Lin C-H, Wong L-T, Hsu J-Y, et al. Relationship between exposure to ozone and exacerbation requiring hospital admission among patients with asthma: a case-control study in central Taiwan. BMJ Open 2022;12:e050861. doi:10.1136/ bmjopen-2021-050861

- Prepublication history and additional supplemental material for this paper are available online. To view these files, please visit the journal online (http://dx.doi.org/10.1136/ bmjopen-2021-050861)

Received 02 March 2021 Accepted 28 January 2022

Check for updates

(c) Author(s) (or their employer(s)) 2022. Re-use permitted under CC BY-NC. No commercial re-use. See rights and permissions. Published by BMJ.

For numbered affiliations see end of article.

Correspondence to

Dr Wen-Cheng Chao; cwc081@hotmail.com

\section{ABSTRACT}

Objective The convergence of asthma and air pollutants in ageing populations is currently a growing health issue worldwide, and hence there is an essential need to investigate the association between exposure to air pollution, particularly ozone $\left(\mathrm{O}_{3}\right)$, and exacerbation requiring admission in patients with asthma.

Setting A case-control study at a tertiary referral hospital in central Taiwan.

Participants We used an asthma cohort, which included 11400 patients with asthma, for the period 2006-2018 at Taichung Veterans General Hospital.

Primary and secondary outcome measures We identified patients who had admitted for exacerbation as cases and selected patients with asthma without exacerbation, matching (1:4) the cases for age, gender and season of exacerbation, as controls. Data on hourly level of air pollutants were obtained from the Taiwan Environmental Protection Administration. We used conditional logistic regression and calculated adjusted ORs (adjORs) with 95\% Cls.

Results We enrolled 11400 participants with asthma, and $4.4 \%$ (501) of them had been admitted for exacerbation. Participants with asthma with exacerbation requiring hospitalisation were exposed to a higher level of $\mathrm{O}_{3}$ 8-hour daily maximum (adj0R $1.009,95 \% \mathrm{Cl} 1.001$ to 1.016 ) and were more likely to have high Charlson Comorbidity Index (CCl $\geq 3$; adjOR 2.198, 95\% $\mathrm{Cl} 1.729$ to 2.794) and asthmachronic obstructive pulmonary disease overlap (adjOR $4.542,95 \% \mathrm{Cl} 3.376$ to 6.611 ) compared with those without exacerbation. The aforementioned associations between exacerbation of asthma requiring hospitalisation and exposure to $\mathrm{O}_{3}$ were similar when defined by either $\mathrm{O}_{3}$ 1-hour daily maximum or $\mathrm{O}_{3} 24$-hour average. Moreover, the $0_{3}$ relevant exacerbation of asthma mainly existed in those aged older than 65 years and patients with medical comorbidities, including gastrointestinal diseases, cardiovascular diseases, neurological diseases, diabetes and renal disease.

Conclusions Our findings highlight the need for vigilance of exposure to $\mathrm{O}_{3}$ among elderly with asthma, particularly those with medical comorbidities. Further studies are warranted to investigate the underlying mechanisms.
Strengths and limitations of this study

- This study linked a hospital-based asthma cohort with a dataset of air pollutants across Taiwan.

- We included a relatively large sample size of people with asthma aged older than 65 years.

- We employed a case-control study design to determine whether exposure to air pollutant was associated with exacerbation of asthma.

- This was a single-centre study; hence, external validation is needed.

\section{BACKGROUND}

Asthma affects nearly 339 million people worldwide in 2016, with a rise in prevalence of $3.5 \%$ compared with that in $2006 .{ }^{1}$ Exacerbation is critical in patients with asthma, and it is estimated that approximately $12.5 \%$ in the USA and $8.4 \%$ of persons with asthma in the UK had one or more asthma exacerbations between 2009 and 2011. ${ }^{2}$ Growing pieces of evidence have shown that environmental triggers, including airborne allergens and air pollutants, may lead to aggravation of allergic diseases including asthma, ${ }^{3}$ and exacerbation of asthma has increasingly been found to be associated with exposure to air pollutants, mainly particulate matter (PM) and ozone $\left(\mathrm{O}_{3}\right){ }^{45}$

$\mathrm{O}_{3}$, a solar intensity-dependent air pollutant, is currently an increasing health hazard worldwide, partly due to the warming climate. ${ }^{6-8}$ Exposure to $\mathrm{O}_{3}$ is estimated to be responsible for 470000 respiratory deaths per year worldwide and may increase up to $70 \%$ by 2050 in the UK. ${ }^{6}$ Di et al, investigating the US Medicare population with approximately 60 million people 65 years of age or older between 2000 and 2013, reported that an increase of $10 \mathrm{ppb}$ in $\mathrm{O}_{3}$ was associated with an increase in all-cause mortality of $1.1 \%$ (95\% CI 1.0 to 1.2$){ }^{7}$ 
Accumulating pieces of evidence have shown that exposure to $\mathrm{O}_{3}$ correlated with exacerbation of asthma. ${ }^{8-10}$ Goodman et al investigated the effects of $\mathrm{O}_{3}$ on asthma exacerbation in Texas and found a positive association between increased $\mathrm{O}_{3}$ exposure and hospital admission due to asthma in patients aged 5-14 years. ${ }^{9}$ Sacks et al, using a time-stratified case-crossover study in North Carolina, also reported a positive association between $\mathrm{O}_{3}$ and asthma-associated emergency department visits in children (5-17 years of age). ${ }^{10}$ However, in most studies investigating the impact of $\mathrm{O}_{3}$ on asthma exacerbation, the target population is children with asthma. ${ }^{11-14}$ The effect of $\mathrm{O}_{3}$ on asthma in adulthood remains unclear.

Given the distinct pathogenesis of asthma in the elderly, ${ }^{15}$ there is a crucial need to address the impact of air pollutant on exacerbation of asthma in the elderly. In the present study, we linked the database of asthma cohort at Taichung Veterans General Hospital (TCVGH) and data on hourly levels of air pollutants across Taiwan obtained from Taiwan's Environmental Protection Administration (EPA). We conducted a case-control study using data obtained from the two aforementioned datasets between 2006 and 2018 to determine the associations between exposure to air pollutants and asthma exacerbation requiring admission.

\section{METHODS}

\section{Study population}

This retrospective study was conducted at TCVGH, a tertiary-care referral hospital with approximately 1500 beds in central Taiwan. Data regarding demographic information, Charlson Comorbidity Index (CCI), ambulatory/inpatient diagnoses and medications were obtained from the TCVGH clinical data warehouse. ${ }^{16} \mathrm{We}$ enrolled patients with asthma, defined by having at least three ambulatory visits or one hospital admission with a diagnosis of asthma, at TCVGH between 2006 and 2018 . Patients with asthma and had at least three ambulatory visits with a diagnosis of chronic obstructive pulmonary disease (COPD) was classified as asthma-COPD overlap (ACO). ${ }^{17}$

\section{Measurement of exposure to air pollutants}

EPA has established approximately 60 air quality monitoring stations across Taiwan, and we used the hourly levels of air pollutants 1 day prior to the index date of the nearest air quality monitoring station for analyses. ${ }^{18}$ The air pollutants analysed in this study included particulate matter $<2.5 \mu \mathrm{m}$ in size (PM2.5), particulate matter $<10$ $\mu \mathrm{m}$ in size (PM10), ozone $\left(\mathrm{O}_{3}\right)$, nitrogen dioxide $\left(\mathrm{NO}_{9}\right)$, sulfur dioxide $\left(\mathrm{SO}_{2}\right)$ and carbon monoxide $(\mathrm{CO})$. Notably, unlike the gradual decline of $\mathrm{O}_{3}$ in countries such as the USA and France, ${ }^{19}{ }^{20}$ increased level of $\mathrm{O}_{3}$ remains a major concern in Taiwan and countries located in the tropical and subtropical areas. ${ }^{21}$ Previous studies including our previous study have shown that the completeness of the Taiwan's air quality data appears to be high, with the exception of eastern Taiwan, which had some missing data; therefore, the data on air pollutants in this study should be considered complete given that we used data for central Taiwan. ${ }^{22} 23$

\section{Study design}

This study employed matched case-control design, and we used a strict definition of asthma-specific hospitalisation, that is, the primary admission diagnosis was asthma and systemic corticosteroid was administered on admission, to define exacerbation in patients with asthma. ${ }^{24}$ We matched the index season to mitigate the potential season-relevant confounding effect in the present study. Among the asthma cohort, we randomly selected those without exacerbation matching (1:4) by sex, age $( \pm 3$ years) and the index season.

\section{Statistical analysis}

The numbers of patients were expressed as percentages for categorical variables, and mean $\pm \mathrm{SD}$ was used for continuous variables. Categorical variables were compared using the $\chi^{2}$ test or the Fisher's exact test, and continuous variables were compared using the t-test. Variables were considered as candidates for inclusion in the multivariable model if the associated univariable $\mathrm{p}$ value was lower than $0.20 .^{25}$ The association between the risk for exacerbation of asthma and exposure to air pollutants was examined using a multivariable conditional logistic regression analysis after adjusting for age, gender and index season. Adjusted OR (adjOR) and the corresponding $95 \%$ CI for each variable were presented. In the present study, we used three distinct indicators to address the impact of $\mathrm{O}_{3}$, namely, 1-hour daily maximum concentrations, 8-hour daily maximum concentrations and 24-hour average concentrations. ${ }^{26}$ All data were analysed using the Statistical Analysis Software program, V.9.3 (SAS Institute). A p value $<0.05$ was considered statistically significant.

\section{RESULTS}

\section{Demographic data of enrolled participants}

A total of 11400 patients with asthma were eligible for analyses, and $4.4 \%$ (501) of them had been admitted for exacerbation of asthma during the study period. We selected comparable controls by matching (1:4) for age ( \pm 3 years), gender and index season. In total, 1988 matched controls were selected. Four $(0.8 \%, 4 / 501)$ patients with asthma with exacerbation were excluded due to the lack of matched control subjects (figure 1). We found that patients with asthma with exacerbation requiring hospitalisation had a higher CCI $(3.72 \pm 2.99$ vs 2.68 $\pm 2.56, \mathrm{p}<0.01$ ), exposure to PM (PM2.5, 28.92 \pm 17.73 vs $27.45 \pm 16.49 \mathrm{mg} / \mathrm{m}^{3}, \mathrm{p}=0.09$; PM10, $51.26 \pm 31.49$ vs $48.87 \pm 26.05 \mathrm{mg} / \mathrm{m}^{3}, \mathrm{p}=0.16$ ), were more likely to have ACO $(28.4 \%$ vs $9.5 \%, \mathrm{p}<0.01)$, and exposure to a higher level of $\mathrm{O}_{3}\left(\mathrm{O}_{3}\right.$ 1-hour daily maximum, $57.24 \pm 20.25$ vs $55.24 \pm 20.94 \mathrm{ppb}, \mathrm{p}=0.05 ; \mathrm{O}_{3}$ 8-hour daily maximum, 


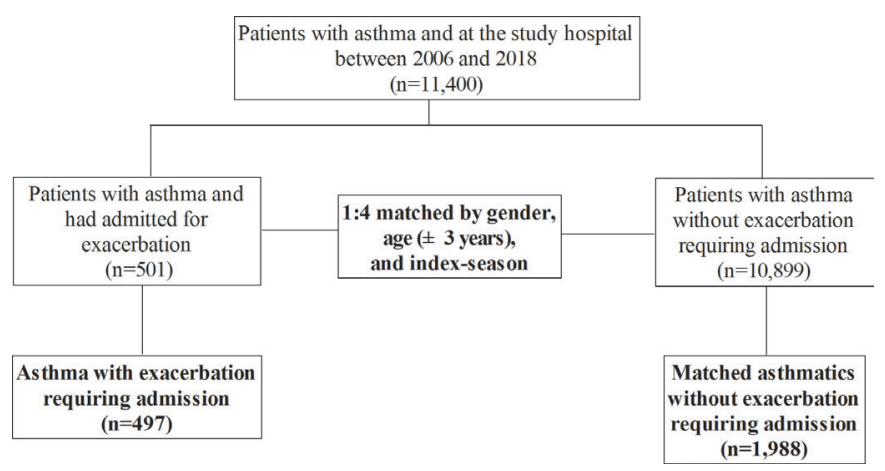

Figure 1 Flowchart of subject enrolment.

$46.42 \pm 16.91$ vs $44.54 \pm 17.28 \mathrm{ppb}, \mathrm{p}=0.03 ; \mathrm{O}_{3}$ 24-hour average, $28.66 \pm 10.26$ vs $27.53 \pm 10.74, \mathrm{p}=0.03$ ) (table 1 ).

\section{Association between variables and incident asthma exacerbation requiring admission}

Among the three indicators of $\mathrm{O}_{3}$ exposure, $\mathrm{O}_{3}$ 8-hour daily maximum is currently the representative indicator for the impact of exposure to $\mathrm{O}_{3}$ on exacerbation of asthma; therefore, we used $\mathrm{O}_{3}$ 8-hour daily maximum in the following multivariable logistical regression. ${ }^{26}$ Intriguingly, in contrast to the positive association between the level of $\mathrm{O}_{3}$ and hot summers, we found the level of $\mathrm{O}_{3}$ was lower in the summer compared with levels seen in the other seasons (online supplemental figure 1). Similar findings with regard to a low $\mathrm{O}_{3}$ level in summer have been reported in previous Taiwanese studies, and meteorological conditions and frequent typhoons might explain the low levels of $\mathrm{O}_{3}$ in summer in central Taiwan. ${ }^{27} 28$ Therefore, we further matched the index season in this study. A conditional logistic regression model, adjusted for age, sex and index season, showed that patients with asthma with exacerbation requiring hospitalisation had a higher $\mathrm{O}_{3}$ 8-hour daily maximum (adjOR 1.009, 95\% CI 1.001 to 1.016) and were more likely to have ACO (adjOR $4.542,95 \%$ CI 3.376 to 6.611 ) as well as high CCI score (CCI $\geq 3$; adjOR 2.198, 95\% CI 1.729 to 2.794) compared with patients with asthma without exacerbation (table 2).

Table 1 Characteristics and exposures to air pollutants of enrolled subjects with asthma

\begin{tabular}{|c|c|c|c|c|}
\hline & $\begin{array}{l}\text { All } \\
\mathrm{N}=2485\end{array}$ & $\begin{array}{l}\text { Asthma with exacerbation } \\
n=497\end{array}$ & $\begin{array}{l}\text { Asthma without exacerbation } \\
n=1988\end{array}$ & $P$ value \\
\hline \multicolumn{5}{|l|}{ Demographic data } \\
\hline Age (years) & $64.03 \pm 15.91$ & $64.6 \pm 16.29$ & $63.89 \pm 15.81$ & 0.38 \\
\hline Age group & & & & 0.99 \\
\hline $20-49$ & 436 (17.55\%) & 86 (17.30\%) & 350 (17.61\%) & \\
\hline $50-64$ & $666(26.8 \%)$ & $135(27.16 \%)$ & $531(26.71 \%)$ & \\
\hline Sex (female) & $1740(70.02 \%)$ & $348(70.02 \%)$ & $1392(70.02 \%)$ & 1.00 \\
\hline \multicolumn{5}{|l|}{ Index season } \\
\hline Spring & 735 (29.58\%) & 147 (29.58\%) & 588 (29.58\%) & 1.00 \\
\hline Summer & $510(20.52 \%)$ & $102(20.52 \%)$ & $408(20.52 \%)$ & \\
\hline Autumn & $535(21.53 \%)$ & 107 (21.53\%) & $428(21.53 \%)$ & \\
\hline $\mathrm{PM} 10\left(\mathrm{~g} / \mathrm{m}^{3}\right)$ & $49.3 \pm 27.24$ & $51.26 \pm 31.49$ & $48.87 \pm 26.05$ & 0.16 \\
\hline \multicolumn{5}{|l|}{$\mathrm{O}_{3}$} \\
\hline $\mathrm{O}_{3}(1$-hour maximum, ppb) & $55.64 \pm 20.81$ & $57.24 \pm 20.25$ & $55.24 \pm 20.94$ & 0.05 \\
\hline $\mathrm{O}_{3}$ (8-hour maximum, ppb) & $44.92 \pm 17.22$ & $46.42 \pm 16.91$ & $44.54 \pm 17.28$ & 0.03 \\
\hline $\mathrm{O}_{3}(24$ hours average, $\mathrm{ppb})$ & $27.75 \pm 10.65$ & $28.66 \pm 10.26$ & $27.53 \pm 10.74$ & 0.03 \\
\hline $\mathrm{SO}_{2}(\mathrm{ppb})$ & $2.83 \pm 1.34$ & $2.85 \pm 1.35$ & $2.82 \pm 1.34$ & 0.67 \\
\hline $\mathrm{CO}(\mathrm{ppm})$ & $0.41 \pm 0.19$ & $0.41 \pm 0.19$ & $0.40 \pm 0.19$ & 0.39 \\
\hline $\mathrm{NO}_{2}(\mathrm{ppb})$ & $14.07 \pm 6.97$ & $14.14 \pm 7.05$ & $14.05 \pm 6.95$ & 0.81 \\
\hline Temperature $\left({ }^{\circ} \mathrm{C}\right)$ & $22.32 \pm 5.35$ & $22.57 \pm 5.29$ & $22.25 \pm 5.37$ & 0.24 \\
\hline Relative humidity (\%) & $72.76 \pm 8.39$ & $72.44 \pm 8.11$ & $72.84 \pm 8.46$ & 0.33 \\
\hline
\end{tabular}

Data are presented as mean \pm SD and $\mathrm{N}(\%)$

$\mathrm{CCl}$, Charlson Comorbidity Index; $\mathrm{CO}$, carbon monoxide; $\mathrm{NO}_{2}$, nitrogen dioxide; $\mathrm{O}_{3}$, ozone; $\mathrm{PM} 10$, particulate matter $<10 \mu \mathrm{m}$; $\mathrm{PM} 2.5$, particulate matter <2.5 $\mu$ m; $\mathrm{SO} 2$, sulfur dioxide. 
Table 2 Crude and adjusted ORs for the association between incident hospitalised exacerbation of asthma and variables

\begin{tabular}{|c|c|c|c|c|}
\hline \multirow[b]{2}{*}{ Variables } & \multicolumn{2}{|l|}{ Univariable analysis } & \multicolumn{2}{|c|}{ Multivariable conditional regression } \\
\hline & Crude OR (95\% Cl) & $P$ value & Adjusted OR (95\% Cl) & $P$ value \\
\hline Age & $1.003(0.997$ to 1.009$)$ & 0.37 & - & - \\
\hline Season & $1.000(0.784$ to 1.276$)$ & 1.00 & - & - \\
\hline $\mathrm{ACO}$ & 5.121 (3.830 to 6.846$)$ & $<0.001$ & 4.542 (3.376 to 6.11$)$ & $<0.001$ \\
\hline PM2.5 & 1.006 (1.000 to 1.012$)$ & 0.057 & $0.999(0.991$ to 1.006$)$ & 0.754 \\
\hline $\mathrm{O}_{3}$ (8-hour maximum) & $1.007(1.001$ to 1.013$)$ & 0.020 & $1.009(1.001$ to 1.016$)$ & 0.025 \\
\hline
\end{tabular}

ACO, asthma COPD (chronic obstructive pulmonary disease) overlap; $\mathrm{CCl}$, Charlson Comorbidity Index; $\mathrm{O}_{3}$, ozone; PM2.5, particulate matter $<2.5 \mu \mathrm{m}$.

Additionally, we determined the association among distinct indicators for exposure to $\mathrm{O}_{3}$ and found that $\mathrm{O}_{3}$ 8-hour daily maximum was highly correlated with $\mathrm{O}_{3}$ 1-hour daily maximum $(\mathrm{r}=0.96, \mathrm{p}<0.01)$ and was less likely to be correlated with $\mathrm{O}_{3}$ 24-hour average $(\mathrm{r}=0.84, \mathrm{p}<0.01)$ (table 3). Furthermore, we also used the $\mathrm{O}_{3}$ 1-hour daily maximum and the $\mathrm{O}_{3}$ 24-hour average as indicators for exposure to $\mathrm{O}_{3}$, and the results were consistent with the aforementioned results using $\mathrm{O}_{3}$ 8-hour daily maximum (online supplemental tables 1 and 2). Collectively, we used distinct indicators for $\mathrm{O}_{3}$ exposure and found that exposure to $\mathrm{O}_{3}$ as well as a high CCI was associated with an increased risk for asthma exacerbation requiring hospitalisation.

\section{Impacts of age and underlying comorbidities on the risk of $\mathbf{O}_{3}$-associated exacerbation of asthma}

We next determined the impacts of age and distinct comorbidities on the $\mathrm{O}_{3}$-associated exacerbation of asthma requiring admission. We found that the $\mathrm{O}_{3}$ relevant exacerbation of asthma mainly existed in those aged older than 65 years, and similar trends also existed in the other two age groups, 50-64 years and 20-49 years, with the relatively small case number in the present study (figure 2). With regard to the impacts of distinct underlying comorbidities on the risk of $\mathrm{O}_{3}$-related exacerbation of asthma, we found that $\mathrm{O}_{3}$-associated exacerbation of asthma was significantly associated with a number of comorbidities, including gastrointestinal diseases (peptic ulcer and liver disease), cardiovascular diseases (congestive heart failure, myocardial infarction, peripheral vascular disease, neurological diseases (cerebrovascular disease, dementia and hemiplegia/paraplegia), diabetes and renal disease (figure 3). These findings demonstrated the impacts of distinct comorbidities on $\mathrm{O}_{3}$-associated exacerbation in adult patients with asthma.

\section{DISCUSSION}

In the present case-control study, we used Taiwan's EPA database and the asthma cohort at TCVGH to explore the effects of exposure to air pollutants on exacerbation requiring hospitalisation in patients with asthma. We found that exposure to $\mathrm{O}_{3}$ and coexistent medical comorbidities were independently associated with asthma exacerbation requiring hospitalisation, particularly in those older than 65 years. These findings highlight the need for vigilance regarding exacerbation of asthma in the elderly after exposure to a high $\mathrm{O}_{3}$ environment, particularly for those with medical comorbidities.

$\mathrm{O}_{3}$ is a substantial and growing health concern worldwide. ${ }^{29}$ Madrigano et al, using Bayesian hierarchical model to estimate the mortality risk that can be attributed to $\mathrm{O}_{3}$ in 91 cities across the USA, found that a $10 \mathrm{ppb}$ increase in $\mathrm{O}_{3}$ was associated with a $0.45 \%$ increase in mortality (95\% PI $0.08-0.83$ ) in urban counties and a $0.73 \%$ increase $(95 \%$ CI 0.19 to 1.26$)$ in non-urban counties. ${ }^{30}$ Notably, unlike the gradual decline of $\mathrm{O}_{3}$ in countries including the USA and France, ${ }^{19}{ }^{20}$ increased level of $\mathrm{O}_{3}$ remains a concern in the tropical and subtropical countries, including Taiwan. ${ }^{21}$ In contrast with the gradually decreased levels of PM2.5 from $36.60 \mathrm{mg} / \mathrm{m}^{3}$ in 2006 and $20.70 \mathrm{mg} / \mathrm{m}^{3}$ in 2018, we found persistently elevated levels of $\mathrm{O}_{3}$ during the study period (49.17 ppb in 2006 and $47.81 \mathrm{ppb}$ in 2018) in central Taiwan (online supplemental figure 1). In line with the trend of $\mathrm{O}_{3}$ in Taiwan, Gao et al, investigating the long-term trend of $\mathrm{O}_{3}$ in

Table 3 Pearson's correlation coefficients $\left(r^{2}\right)$ among the three indicators for $\mathrm{O}_{3}$

\begin{tabular}{lccc}
\hline & $\mathbf{O}_{3}$ (1-hour maximum) & $\mathbf{O}_{3}$ (8-hour maximum) & $\mathbf{O}_{3}$ (24-hour average) \\
\hline $\mathrm{O}_{3}(1$-hour maximum) & 1.00 & 0.96 & 0.74 \\
$\mathrm{O}_{3}(8$-hour maximum) & $<0.01$ & 1.00 & 0.84 \\
$\mathrm{O}_{3}(24$-hour average) & $<0.01$ & $<0.01$ & 1.00 \\
\hline
\end{tabular}




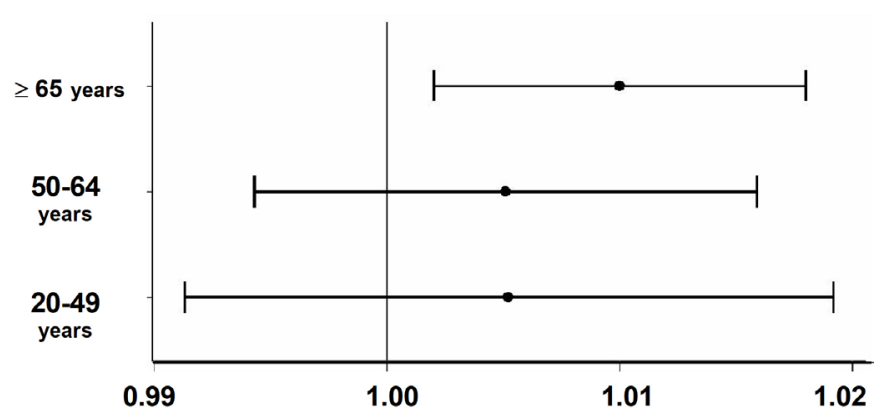

Figure 2 Association between $\mathrm{O}_{3}$ 8-hour daily maximum and risk for asthma exacerbation categorised by age group.

Shanghai, found that $\mathrm{O}_{3}$ increased by $67 \%$, whereas $\mathrm{NOx}$ decreased by $38 \%$ from 2006 to $2015 .^{31}$ Taken together, these pieces of evidence highlight the crucial need to clarify the impact of $\mathrm{O}_{3}$ on health worldwide, particularly in tropical and subtropical areas with a soaring level of $\mathrm{O}_{3}$ in recent decades.

Asthma in the elderly is currently a critical public health issue, especially as there has been a disproportionate increase in individuals aged older than 65 years. Indeed, asthma is increasingly being found to be an important cause of morbidity and mortality in the elderly. ${ }^{15}$ Asthma in the elderly is a complex disease and is frequently attributed to intrinsic rather than allergic asthma. Unlike the predominant Th2 adaptive immunity in allergic asthma, environmental activation of innate immunity appears to play a crucial role in intrinsic asthma. ${ }^{15}$ Sohn et al recently used Bayesian network analysis to explore risk factors for exacerbations in three adult asthma cohorts $(n=1086)$ and found that an increase in eosinophil count was less likely to be associated with asthma exacerbation in the elderly than those in non-elderly. ${ }^{32}$ Furthermore, Kim et al conducted a sputum transcriptomic analysis in 55 elderly patients with asthma and 10 elderly controls and found an increased expression of oxidative phosphorylation, unfolded protein response, myogenesis and epithelial-mesenchymal transition gene sets in the

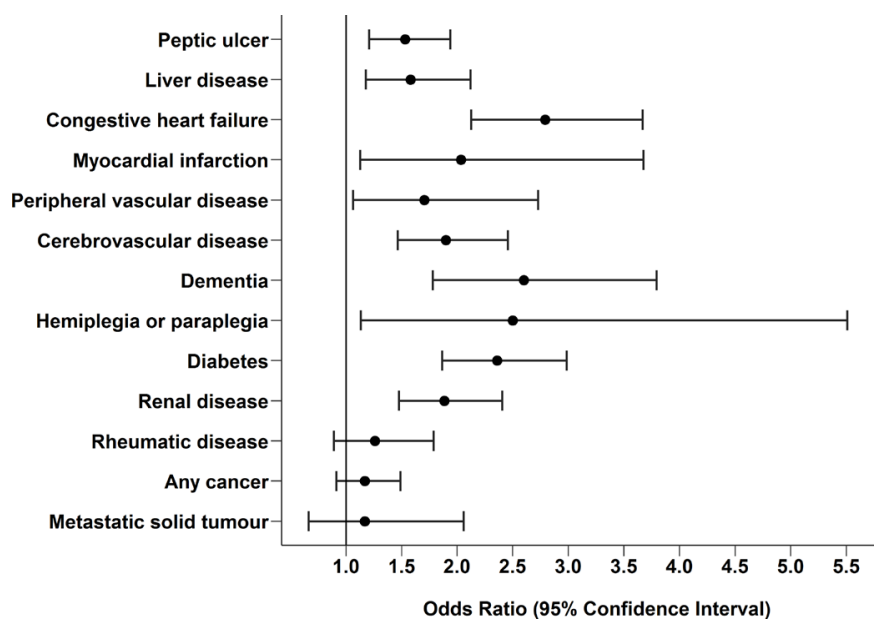

Figure 3 Association between $\mathrm{O}_{3}$ 8-hour daily maximum and risk for asthma exacerbation categorised by comorbidities. elderly with asthma. ${ }^{33}$ Ilmarinen et al, using the data of 170 adults with asthma with 12-year follow-up data, reported that elevation of serum interleukin- 6 as well as C-reactive protein and multi-morbidities were associated with a negative outcome in adults with asthma. ${ }^{34}$ Therefore, the underlying non-allergic pathway might possibly reflect coexisting comorbidities in the elderly with asthma as we have shown in the present study. Furthermore, the association between exposure to $\mathrm{O}_{3}$ and exacerbation of asthma in the elderly as we have shown in the present study might possibly be attributed to the potential $\mathrm{O}_{3}$ mediated augmentation of non-allergic signalling pathways, including innate lymphoid cell-2, airway mucus cell metaplasia and interleukin-33 in the airway. ${ }^{35} 36$ Collectively, there are distinct non-allergic mechanisms underlying asthma in the elderly, and our data provide epidemiological evidence of an association between $\mathrm{O}_{3}$ and asthma in the elderly, particularly those with coexistent comorbidities.

One recently published global study conducted in 20 countries reported crucial differences in the $\mathrm{O}_{3}$ mortality association across countries ${ }^{8}$; however, few studies have been conducted in Taiwan to explore the association between $\mathrm{O}_{3}$ and exacerbation of asthma, particularly in adult persons with asthma. ${ }^{37}$ Lin et al explored the association between cumulative 6-day outpatient visits for asthma and three $\mathrm{O}_{3}$ metrics, including daily 1-hour maximum, 8-hour average maximum and 24-hour average, in Taipei between 2000 and 2009. ${ }^{37}$ The author reported that 24-hour average $\mathrm{O}_{3}$ appeared to be the optimal $\mathrm{O}_{3}$ metric to be associated with the outpatient visits for asthma (relative risk 1.18; 95\% CI 1.00 to 1.39). The results are largely in line with the finding of the present study that showed 24-hour average $\mathrm{O}_{3}$ was a predictor for exacerbation of asthma. Pan et al, using the Taiwanese National Health Insurance Research Database to investigate the effect of air pollutants on the utilisation of healthcare services among patients with asthma between 2000 and 2009 at a seasonal level, found no significant association between $\mathrm{O}_{3}$ and asthma-associated inpatient/outpatient visits. ${ }^{38}$ Given that the authors focused on the association between seasonal average air pollutant exposure and seasonal frequency of healthcare service, the short-term impact of $\mathrm{O}_{3}$ on exacerbation might not be fully explored. Additionally, the study hospital is located in central Taiwan, which has a distinct air pollutant profile due to the mountainous area located to the east of the city, urbanised areas with heavy traffic, as well as a massive power station and industrial region in the western area. This unique and diverse environment warrants further investigation to determine the impact of $\mathrm{O}_{3}$ in persons with asthma. ${ }^{27}$

Most previous studies, including our recently published studies, on the health impact of air pollutants have used levels of air pollutant in residential areas as a surrogate of exposure to air pollution, although this approach might not precisely reflect the exposure to air pollution among individual patients. ${ }^{23}{ }^{39}$ Some 
wearable devices have been proposed to measure the precise exposure of air pollution in individual patients; however, the accuracy of measurements of $\mathrm{O}_{3}$ obtained by wearable devices appears to be lower compared with the standardised measurement of levels of air pollutants conducted by Taiwan's EPA. ${ }^{40}$

There were limitations in this study. First, this was a single-centre study conducted in Taiwan, and our findings may therefore not be generalisable to other populations. Second, owing to the observational nature of this study, we were unable to make causal inferences with respect to exposure to air pollutants and the exacerbation of asthma. Third, the accuracy of asthma diagnosis is a potential concern; however, the study hospital is one of the original hospitals in the Taiwanese pay-forperformance asthma programme. ${ }^{41}$ The diagnosis and management of patients with asthma has been continuously scrutinised. Furthermore, 89.3\% (10180/11400) of patients with asthma had received inhaled corticosteroid, a fundamental medication in the management of asthma, and the accuracy of asthma diagnosis in this study was probably high. The prevalence of ACO and increased risk of exacerbation in patients with ACO were also consistent with previous studies including one Taiwanese population-based study. ${ }^{17}{ }^{42}$ Fourth, we focused on hospitalised exacerbation of asthma, a fundamental indicator for control of asthma, in the present study, and the severity of asthma prior to exacerbation was not assessed. Furthermore, there are some unmeasured confounding factors, such as smoking, occupation exposure and socioeconomic status; nonetheless, these factors likely did not lead to a differential error in this case-control study. Moreover, the stringent definition of asthma exacerbation requiring hospital admission may have led to an underestimation, rather than an overestimation, of the association between exposure to ozone and exacerbation of asthma.

\section{CONCLUSIONS}

The convergence of asthma and air pollutants in ageing populations is an increasing global health threat, particularly the steadily growing threat of $\mathrm{O}_{3}$ in Asian countries, including Taiwan. In the present case-control study, we correlated data from an asthma cohort at TCVGH with data from Taiwan's EPA database to explore the effects of exposure to air pollutants on asthma exacerbation requiring hospital admission. We found that exposure to $\mathrm{O}_{3}$ and medical comorbidities were associated with risk for exacerbation requiring hospitalisation among patients with asthma, particularly elderly individuals with asthma. The evidence presented herein suggests the need for vigilance regarding exposure to $\mathrm{O}_{3}$ among elderly individuals with asthma, particularly those with medical comorbidities. Further studies are warranted to explore strategies aimed at reducing exposure to $\mathrm{O}_{3}$ in high-risk individuals with asthma.
Author affiliations

${ }^{1}$ Department of Medical Research, Taichung Veterans General Hospital, Taichung, Taiwan

${ }^{2}$ Department of Healthcare Management, National Taipei University of Nursing and Health Sciences, Taipei, Taiwan

${ }^{3}$ Department of Public Health, College of Medicine, Fu Jen Catholic University, New Taipei City, Taiwan

${ }^{4}$ Department of Industrial Engineering and Enterprise Information, Tunghai University, Taichung, Taiwan

${ }^{5}$ School of Physical Therapy, Chung-Shan Medical University, Taichung, Taiwan

${ }^{6}$ School of Medicine, China Medical University, Taichung, Taiwan

${ }^{7}$ Department of Critical Care Medicine, Taichung Veterans General Hospital,

Taichung, Taiwan

${ }^{8}$ Colledge of Medicine, Chung Hsing University, Taichung, Taiwan

${ }^{9}$ Big Data Center, Chung Hsing University, Taichung, Taiwan

${ }^{10}$ Department of Automatic Control Engineering, Feng Chia University, Taichung, Taiwan

Contributors Conceived and designed the experiments: C-HL, J-YH and W-CC. Acquired data: C-HL, L-TW and C-HL. Contributed materials/analysis tools: C-HL, L-TW and W-CC. Wrote the paper: C-HL and W-CC. Guarantor of the study: W-CC.

Funding This study was supported in part by grants from Veterans General Hospitals and the University System of Taiwan Joint Research Programme (VGHUST109-V2-2-1, VGHUST109-V2-2-2 and VGHUST109-V2-2-3).

Disclaimer The funders had no role in the study design, data collection and analysis, decision to publish or preparation of the manuscript.

Competing interests None declared.

Patient consent for publication Not applicable.

Ethics approval This study was approved by the Institutional Review Board of the Taichung Veterans General Hospital (TCVGH: CE20044B). All of the data were anonymised data, and informed consent was hence waived.

Provenance and peer review Not commissioned; externally peer reviewed.

Data availability statement All data relevant to the study are included in the article or uploaded as supplementary information. All of the data and materials are provided in the manuscript and the supplemental data.

Supplemental material This content has been supplied by the author(s). It has not been vetted by BMJ Publishing Group Limited (BMJ) and may not have been peer-reviewed. Any opinions or recommendations discussed are solely those of the author(s) and are not endorsed by BMJ. BMJ disclaims all liability and responsibility arising from any reliance placed on the content. Where the content includes any translated material, BMJ does not warrant the accuracy and reliability of the translations (including but not limited to local regulations, clinical guidelines, terminology, drug names and drug dosages), and is not responsible for any error and/or omissions arising from translation and adaptation or otherwise.

Open access This is an open access article distributed in accordance with the Creative Commons Attribution Non Commercial (CC BY-NC 4.0) license, which permits others to distribute, remix, adapt, build upon this work non-commercially, and license their derivative works on different terms, provided the original work is properly cited, appropriate credit is given, any changes made indicated, and the use is non-commercial. See: http://creativecommons.org/licenses/by-nc/4.0/.

\section{ORCID iDs}

Ching-Heng Lin http://orcid.org/0000-0002-2450-6108

Wen-Cheng Chao http://orcid.org/0000-0001-9631-8934

\section{REFERENCES}

1 GBD 2016 Disease and Injury Incidence and Prevalence Collaborators. Global, regional, and national incidence, prevalence, and years lived with disability for 328 diseases and injuries for 195 countries, 1990-2016: a systematic analysis for the global burden of disease study 2016. Lancet 2017;390:1211-59.

2 Suruki RY, Daugherty JB, Boudiaf N, et al. The frequency of asthma exacerbations and healthcare utilization in patients with asthma from the UK and USA. BMC Pulm Med 2017;17:74.

3 Asher I, Dagli E. Environmental influences on asthma and allergy. Chem Immunol Allergy 2004;84:36-101. 
4 Guarnieri M, Balmes JR. Outdoor air pollution and asthma. Lancet 2014;383:1581-92.

5 Goodman JE, Zu K, Loftus CT, et al. Short-term ozone exposure and asthma severity: Weight-of-evidence analysis. Environ Res 2018;160:391-7.

6 Anenberg SC, Horowitz LW, Tong DQ, et al. An estimate of the global burden of anthropogenic ozone and fine particulate matter on premature human mortality using atmospheric modeling. Environ Health Perspect 2010;118:1189-95.

7 Di Q, Wang Y, Zanobetti A, et al. Air pollution and mortality in the Medicare population. N Engl J Med 2017;376:2513-22.

8 Vicedo-Cabrera AM, Sera F, Liu C, et al. Short term association between ozone and mortality: global two stage time series study in 406 locations in 20 countries. BMJ 2020;368:m108.

9 Goodman JE, Zu K, Loftus CT, et al. Ambient ozone and asthma hospital admissions in Texas: a time-series analysis. Asthma Res Pract 2017;3:6.

10 Sacks JD, Rappold AG, Davis JA, et al. Influence of urbanicity and County characteristics on the association between ozone and asthma emergency department visits in North Carolina. Environ Health Perspect 2014;122:506-12.

11 Strickland MJ, Darrow LA, Klein M, et al. Short-term associations between ambient air pollutants and pediatric asthma emergency department visits. Am J Respir Crit Care Med 2010;182:307-16.

12 Rodrigues M, Natário I, do Rosário de Oliveira Martins M. Estimate the effects of environmental determining factors on childhood asthma hospital admissions in Lisbon, Portugal: a time series modelling study. Theoretical and Applied Climatology 2021;143:809-21.

13 Raun LH, Ensor KB, Persse D. Using community level strategies to reduce asthma attacks triggered by outdoor air pollution: a case crossover analysis. Environ Health 2014;13:58.

14 Zheng X-Y, Orellano P, Lin H-L, et al. Short-term exposure to ozone, nitrogen dioxide, and sulphur dioxide and emergency department visits and hospital admissions due to asthma: a systematic review and meta-analysis. Environ Int 2021;150:106435

15 Gibson PG, McDonald VM, Marks GB. Asthma in older adults. Lancet 2010;376:803-13.

16 Deyo RA, Cherkin DC, Ciol MA. Adapting a clinical comorbidity index for use with ICD-9-CM administrative databases. J Clin Epidemiol 1992;45:613-9.

17 Venkata AN. Asthma-COPD overlap: review of diagnosis and management. Curr Opin Pulm Med 2020;26:155-61.

18 Taiwan Air Quality Monitoring Net work. Environmental protection administration T. Available: https://taqm.epa.gov.tw/taqm/en/b0201. aspx [Accessed 10 Aug 2020].

19 Agency USEP. Trends in ozone adjusted for weather conditions. Available: https://www.epa.gov/air-trends/trends-ozone-adjustedweather-conditions [Accessed 10 Jul 2020].

20 Sicard P, Serra R, Rossello P. Spatiotemporal trends in ground-level ozone concentrations and metrics in France over the time period 1999-2012. Environ Res 2016;149:122-44.

21 Wang T, Xue L, Brimblecombe P, et al. Ozone pollution in China: a review of concentrations, Meteorological influences, chemical precursors, and effects. Sci Total Environ 2017;575:1582-96.

22 Lee M, Lin L, Chen C-Y, et al. Forecasting air quality in Taiwan by using machine learning. Sci Rep 2020;10:4153.

23 Chen $\mathrm{H}-\mathrm{H}$, Yong Y-M, Lin C-H, et al. Air pollutants and development of interstitial lung disease in patients with connective tissue disease: a population-based case-control study in Taiwan. BMJ Open 2020;10:e041405.
24 Fuhlbrigge A, Peden D, Apter AJ, et al. Asthma outcomes: exacerbations. J Allergy Clin Immunol 2012;129:S34-48.

25 Bursac Z, Gauss CH, Williams DK, et al. Purposeful selection of variables in logistic regression. Source Code Biol Med 2008;3:17.

26 Li X, Chen Q, Zheng X, et al. Effects of ambient ozone concentrations with different averaging times on asthma exacerbations: a metaanalysis. Sci Total Environ 2019;691:549-61.

27 Tsai D-H, Wang J-L, Wang C-H, et al. A study of groundlevel ozone pollution, ozone precursors and subtropical Meteorological conditions in central Taiwan. J Environ Monit 2008;10:109-18.

28 Lin C-Y, Wang Z, Chou CC-K, et al. A numerical study of an autumn high ozone episode over southwestern Taiwan. Atmos Environ 2007;41:3684-701.

29 Zhang JJ, Wei Y, Fang Z. Ozone pollution: a major health hazard worldwide. Front Immunol 2019;10:2518.

30 Madrigano J, Jack D, Anderson GB, et al. Temperature, ozone, and mortality in urban and non-urban counties in the northeastern United States. Environ Health 2015;14:3.

31 Gao W, Tie X, Xu J, et al. Long-term trend of $\mathrm{O}_{3}$ in a mega City (Shanghai), China: Characteristics, causes, and interactions with precursors. Sci Total Environ 2017;603-604:425-33.

32 Sohn KH, Song WJ, Park JS, et al. Risk factors for acute exacerbations in elderly asthma: what makes asthma in older adults distinctive? Allergy Asthma Immunol Res 2020;12:443-53.

$33 \mathrm{Kim} \mathrm{BK}$, Lee HS, Sohn KH, et al. Different biological pathways are up-regulated in the elderly with asthma: sputum transcriptomic analysis. Allergy Asthma Immunol Res 2019;11:104-15.

34 Ilmarinen P, Tuomisto LE, Niemelä O, et al. Comorbidities and elevated IL-6 associate with negative outcome in adult-onset asthma. Eur Respir J 2016;48:1052-62.

35 Yang Q, Ge MQ, Kokalari B, et al. Group 2 innate lymphoid cells mediate ozone-induced airway inflammation and hyperresponsiveness in mice. J Allergy Clin Immunol 2016:137:571-8.

36 Harkema JR, Wagner JG. Innate lymphoid cell-dependent airway epithelial and inflammatory responses to inhaled ozone: a new paradigm in pathogenesis. Toxicol Pathol 2019;47:993-1003.

37 Lin Y-K, Chang S-C, Lin C, et al. Comparing ozone metrics on associations with outpatient visits for respiratory diseases in Taipei metropolitan area. Environ Pollut 2013;177:177-84.

38 Pan $\mathrm{H}-\mathrm{H}$, Chen C-T, Sun H-L, et al. Comparison of the effects of air pollution on outpatient and inpatient visits for asthma: a populationbased study in Taiwan. PLoS One 2014;9:e96190.

39 Chen $\mathrm{H}-\mathrm{H}$, Lin $\mathrm{C}-\mathrm{H}$, Hsieh T-Y, et al. Factors associated with incident severe pulmonary arterial hypertension in systemic autoimmune rheumatic diseases: a nationwide study. Rheumatology 2021;60:5351-61.

40 Salamone F, Masullo M, Sibilio S. Wearable devices for environmental monitoring in the built environment: a systematic review. Sensors 2021;21. doi:10.3390/s21144727. [Epub ahead of print: 10 Jul 2021]

41 Wang C-Y, Lai C-C, Wang Y-H, et al. The prevalence and outcome of short-acting $\beta 2$-agonists overuse in asthma patients in Taiwan. NPJ Prim Care Respir Med 2021;31:19.

42 Shantakumar S, Pwu R-F, D'Silva L, et al. Burden of asthma and COPD overlap (ACO) in Taiwan: a nationwide population-based study. BMC Pulm Med 2018;18:16. 